\title{
IMPACT OF VIRTUAL REALITY EXPERIENCE ON ACCESSIBILITY OF CULTURAL HERITAGE
}

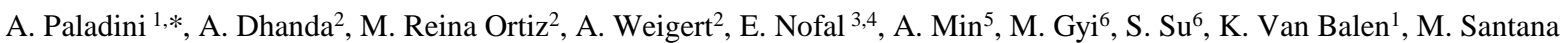 \\ Quintero $^{2}$ \\ ${ }^{1}$ Raymond Lemaire International Centre for Conservation (RLICC), KU Leuven, Kasteelpark Arenberg 1, 3001 \\ Leuven, Belgium - alice.paladini@studentkuleuven.be, koenraad.vanbalen@kuleuven.be \\ ${ }^{2}$ Carleton Immersive Media Studio (CIMS), Carleton University, Ottawa, Canada - (adhanda, aweigert)@ cims.carleton.ca, \\ (miquel.reinaortiz, mario.santana)@ carleton.ca \\ ${ }^{3}$ Research[x]Design, Department of Architecture, KU Leuven, Kasteelpark Arenberg 1, 3001 Leuven, Belgium \\ ${ }^{4}$ Department of Architecture, Assiut University, 71516 Assiut, Egypt - eslam.nofal@kuleuven.be \\ ${ }^{5}$ Department of Archaeology and National Museum, Bagan, Myanmar \\ ${ }^{6}$ Mandalay Technological University, Mandalay, Myanmar
}

KEY WORDS: Accessibility, Virtual Reality, wall paintings, Conservation, Cultural Heritage, Bagan, Myanmar

\begin{abstract}
:
Accessibility plays a main role among the aspects that contribute to the conservation of Cultural Heritage sites. Seismic stability, fragility of the artefacts, conflicts, deterioration, natural disasters, climate change and visitors' impact are only some of the possible causes that might lead to the inaccessibility of a heritage site for both researchers and visitors.

The increasing potential of Information and Communication Technologies (ICT) in the conservation field has resulted in the development of Augmented and Virtual reality (AR and VR) experiences. These ones can be very effective for what concerns the description of the visual experience, but also improve the understanding of a site and even became analytic research tools.

This paper presents an inaccessible Buddhist temple in the Myanmar city of Bagan as a case study for the realization of a VR experience that aims at providing accessibility to knowledge and therefore a better understanding of the cultural value. In order to evaluate the effectiveness of the VR for this purpose, a user study has been conducted and its results are reported.
\end{abstract}

\section{ACCESSIBILITY: BEYOND THE PHYSICAL} MANNER

Accessibility is not a secondary aspect of conservation, but a fundamental condition for Cultural Heritage. Something becomes heritage when people decide that it conveys certain values. Therefore, accessibility is essential for something to become heritage (Nordic Council of Ministers, 2009). Guarantee the public accessibility to cultural heritage sites should therefore be a prerequisite to any conservative intervention.

The concept of accessibility, is strongly bound with the social dimension of architecture and the search for solutions that would improve and simplify everyday life despite social, political and economic conditions; that is the reason why it needs to be addressed as a tool that can lead to the cohesion of a community instead of a mere regulatory exercise (Scarpati, 2016). The cultural debate around the role of architecture in raising public awareness about the need for inclusion has been given new life thanks to the development of new technologies that can overcome physical and sensory barriers (Conti et al., 2014).

When talking about accessibility, it is common to refer to the principle of inclusivity and therefore to people with mobility impairments. Physical accessibility of a building or a site often requires additions and modifications in order to guarantee safety for the visitors and avoid discrimination for those ones who have mobility limitations. Architectural barriers can be usually overcome by making interventions that might be either temporary or become real architectural exercises in which the combination of old and new give birth to a contemporary interpretation of the cultural heritage (Arenghi, 2016). On the other hand, these sorts of interventions, if not corroborated by a proper understanding of the site, can lead to a loss of heritage value. The 9th chapter of the Venice Charter states that "any extra work which is indispensable must be distinct from the architectural composition and must bear a contemporary stamp". This statement begs the question of what does actually represent our time and consequently which kind of intervention would best represent the contemporary research contribution to the conservation field.

In its broadest meaning, accessibility does not only refer to physical and perceptual barriers, but also to the practice of conveying knowledge and understanding about a specific site through the experience (Treccani et al., 2016). It is in these terms that the concept of "Inclusive Design" should be addressed: accessibility as equalization of the experience for everybody on the enjoyment and on the understanding level (Puyuelo et al., 2013).

However, conservation practices can sometimes be incompatible with the right to access a site and enjoy its beauty. It is not appropriate to guarantee the access to a cultural site whenever its preservation might be in danger due to the fragility of the site. This sort of reflections lead to the difficult part of defining to what extent accessibility should be allowed before it becomes damaging.

Two of the most famous cases are represented by the Lascaux and Chauvet caves in southwest France. For both these caves, a

\footnotetext{
* Corresponding author
} 
facsimile was realized in order to allow tourists to get knowledge about these cultural heritage sites while protecting the fragile condition of the real caves. When it is not possible to guarantee the safety of visitors and researchers as well as the preservation of the site, physical accessibility should not be an option, but this does not mean that these heritage sites are prevented from being experienced and, therefore, understood.

The traditional relocation and replication methods have been demonstrated to usually lack in showing the original look of the sites and in recreating their actual material quality, but the last decades have seen the development of Information and Communication Technologies (ICT), which can provide useful support for the understanding of cultural heritage (Zhou et al, 2012). One of the main task of contemporary research is therefore to investigate the best application and qualities that technologies such as Augmented and Virtual Reality should meet in order to have an effective role in the conservation of cultural heritage. However, it is important to always remember that all new technologies and software's must be at the dependence of conservation scope.

\section{CASE STUDY: MYIN-PYA-GU TEMPLE IN BAGAN}

With more than 3.000 monuments in its archaeological zone, Bagan is one of the six most visited places in Myanmar. This incredible built heritage includes stupas (described as solid inaccessible reliquaries), temples (with accessible interior spaces) monasteries, and also ordination halls, fortifications and technical architectures. The great majority of these structures has been built between the 11th and the 13th century, during the so-called "Bagan period" (Stadtner, 2013). Back then, Bagan was indeed the first capital of the Burmese empire and therefore the most important religious centre. The merit-making Buddhist tradition, which requires people to intentionally do good actions in order experience better circumstances in their future rebirths, is the base of Bagan incredible archiectural landscape. Building stupas and temples was in fact considered to be a source of great merit and many donors were therefore attracted to donate funds for their construction.

The territory of Myanmar in characterized by conditions that can endanger the conservation and accessibility to its heritage. Due to its geographic location, this country is intensively prone to strong earthquakes and flooding.

The Myin-pya-gu temple (Figure 1) is currently inaccessible due to a high degree of uncertainty about structural behaviour and soundness of the laod bearing structures, as well as, and the the state of conservation of its mural paintings. Given these conditions, Myin-pya-gu is presented as a perfect case study for the realization of a VR experience and to verify that VR is effective at communicating cultural value.

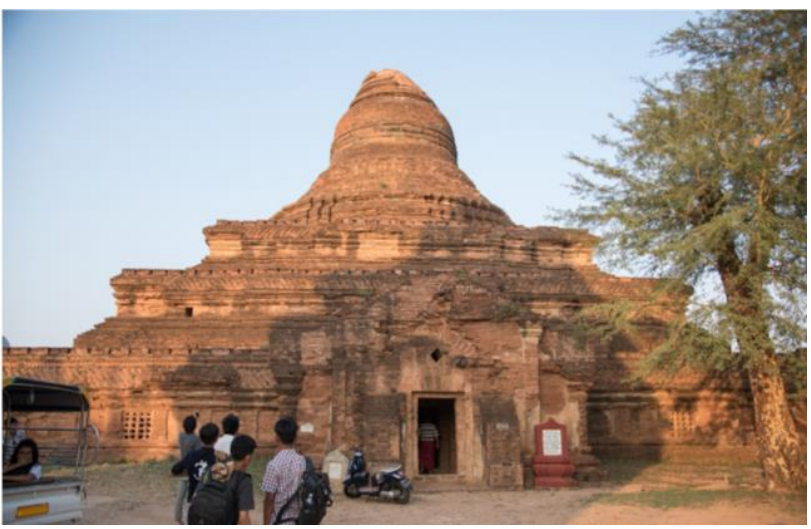

Figure 1. Myin-pya-gu. West façade
Located South of Bagan City Wall, Myin-pya-gu is one of the 45 structures attributed to the $11^{\text {th }}$ century in the Inventory of Monuments at Pagan (Pichard, 2002).It was built between the end of Anawrahta's reign (1044-1077) and the beginning of Sawlu's one (1077-1084): tablets with the signatures of both the kings have been found inside the temple (Luce, 1969). According to Pichard's size classification based on the external dimension of the ground plan, Myin-pya-gu, with its $34,26 \mathrm{x}$ 37,9 meters, is considered a large temple. Its maximum height measures 23.43 meters but only one floor was supposed to be accessed by the devotees.

Interestingly, from outside, this temple could be confused with a stupa. Most temples end with a square tower instead, but Myinpya-gu has a bell-shaped dome and the ringed conical spire. The temple is a combination of the stupa type with temple/image house one (Koller, 2017). The element that does actually identify this building as a temple is the fact that its base is accessible and hallowed to create corridors and shrines with Buddha's statues.

The temple can be divided in two parts: the main body - which contains the accessible parts of the temple - and the upper part. The main body is topped with a square terrace with sloping roof. The upper part is made of two square terraces with three projections and sloping roofs, an octagonal terrace with three projections and a circular bell-shaped dome with a ringed conical spire on top (Figure 2).

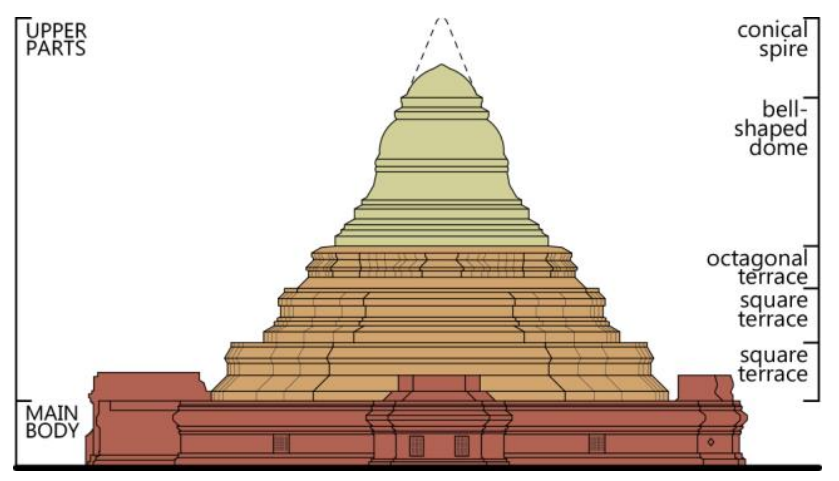

Figure 2. Architectural analysis

The terraces were probably enriched by corner stupas, but, due to the absence of external stairs, they were not designed to be accessed by devotees.

Myin-pya-gu belongs to the category of the full core temples: its centre is in fact made of full bricks, probably to provide better stability for supporting the weight of the central stupa (Pichard, 2002).

The temple is characterized by a square plan with projecting elements in the centre of each side. The one on the West side hosts the only entrance to the temple and it is made of a porch and a vestibule, while the other three projecting volumes accommodate chapels with devotional sculptures of Buddha against the outer walls (Figure 3).

A vaulted corridor that stretches around the solid core connects the three chapels to the entrance and its presence can be guessed from the outside due to the perforated windows that are located at the end of each side of it.

The inner walls of the corridors are enriched with highly carved trefoil niches accommodating brick sculptures representing Buddha in various positions, while on the outer walls there are richly painted mural decorations. From the centre of each inner wall of the corridor, a narrow tunnel stretches into the core of the temple to a small shrine where the principal and most sacred images are located. Small plain perforated windows at the 
corners of the corridors are the only openings through which the light can get into the temple, so that the interiors are extremely dark and the atmosphere is densely devotional.
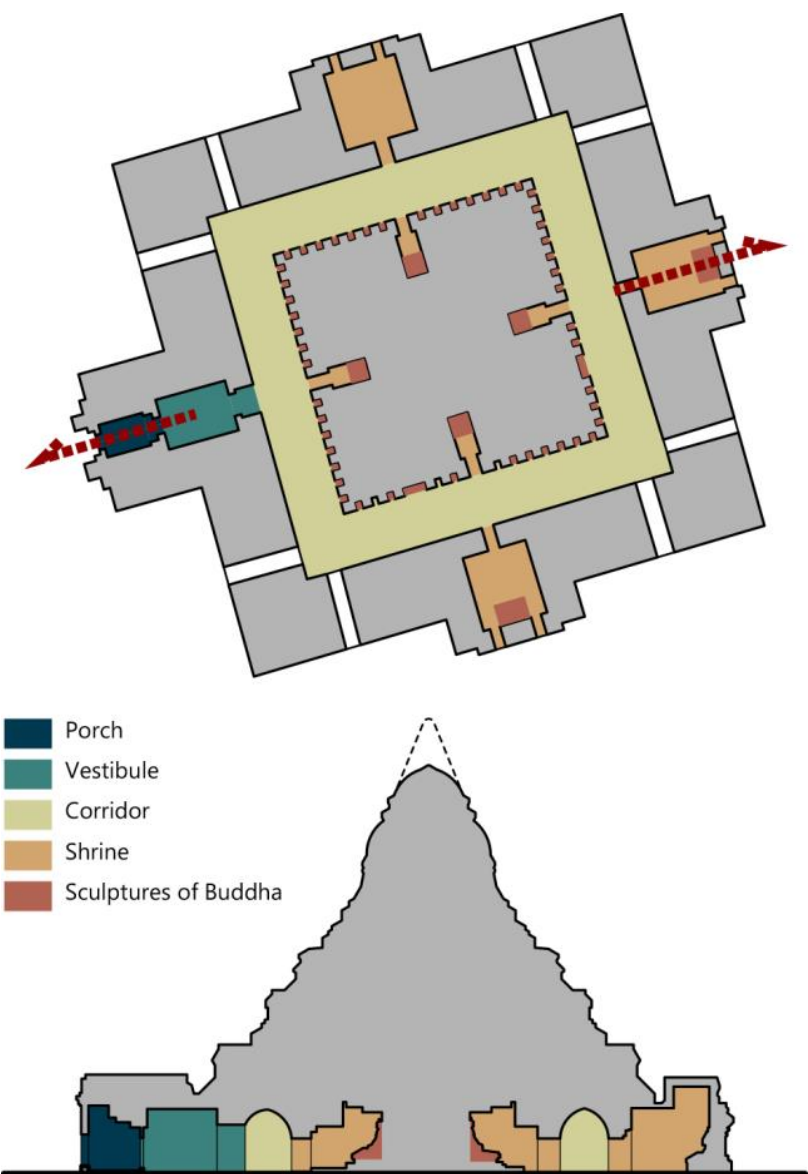

Figure 3. Architectural analysis

\section{METODOLOGY}

\subsection{Survey}

Within the framework of a workshop about "Conserving Built Heritage for Posterity: Bagan Workshop 2018", Carleton University, Mandalay Technological University, and Myanmar's Department of Archaeology (DoA) have been involved in a survey campaign the aimed at recording 4 temples in the archaeological area of Bagan to assess their state of conservation using appropriate technologies.

The exteriors of Myin-pya-gu were recorded using both photogrammetry and laser scanning. Due to the poor lightening conditions, the interior of the temple was documented using photogrammetry with diffused flashes, and intensity based laser scanning (Figure 4).

\subsection{Development of the Virtual Reality experience}

Understanding the theoretical framework of VR and pros and cons of its use is fundamental for a correct interaction the technology. One of the complaints that is usually made against VR is that, although it is considered to be highly enjoyable, it lacks in rendering the same level of details of high resolution photography (John et al, 2017).

The goal of the process was to find a way to keep a high quality geometry in a real-time environment. In order to do this, the

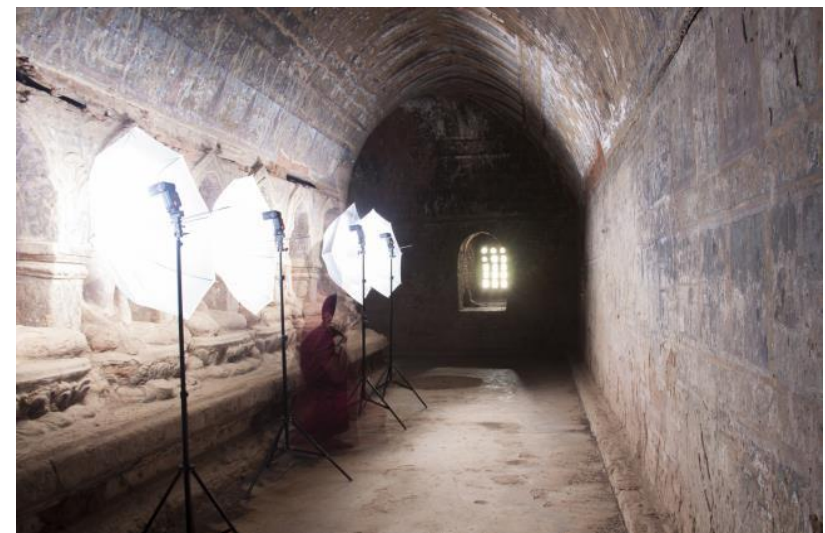

Figure 4. The photogrammetric lighting setup

point cloud and photogrammetry data of Myin-pya-gu was combined using Reality Capture. This photogrammetry software was used over others - Agisoft Photoscan, Bentley Context Capture, etc. - because of its processing speed, and because the output mesh size is not limited by the user's RAM (Remondino et al., 2017).

The high-poly mesh created with from photogrammetry was too heavy to be used in a game engine; it needed to be decimated. The 3D modelling program Zbrush was used to decimate the high-poly mesh to a more manageable low-poly mesh. Next, mesh maps were created to simulate the original details on the resulting low-poly model. In particular, albedo colour maps (or texture), normal, ambient occlusion, roughness and metallic maps were used for this example. Normal maps use RGB values to encode surface normal directions and, when they are baked from a high poly to a low poly, they create an impression of depth that can be applied on a low-poly mesh to fake the details of the high poly one (Figure 5).

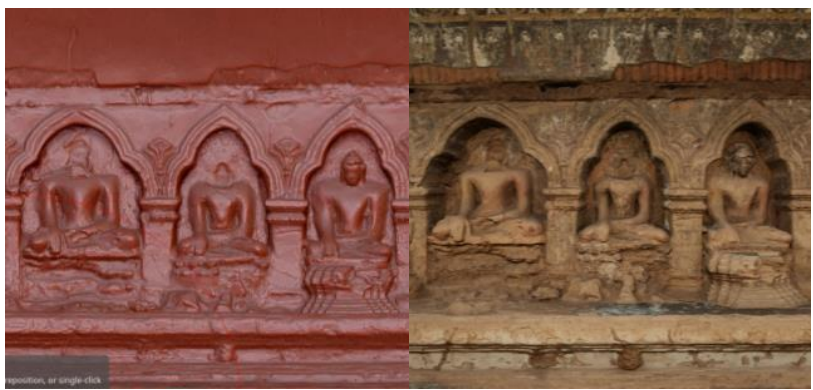

Figure 5. Low-poly compared with the final result

On the other hand, Ambient Occlusion maps approximate the inner shadows of objects when they are under diffuse lighting, while Roughness and Metallic maps are responsible for showing the irregularities and the metallic parts of a surface (McDermott, 2018). Thanks to this technology, it was possible to create a computer game and a VR experience very high in quality and resembling the features of the original surfaces of the temple, but light enough to be run.

The low-polys were then imported in Unreal Engine by Epic Games, a free to use game engine which is easy to use for noncoders thanks to the Blueprints Visual Scripting system.

Both a computer game and a VR experience were created using this software (Figure 6). The first one does not require a headset and, consequently, does not provide an immersive experience. Another difference between the two products stands in the way of moving around the virtual environment. In the game, the arrows of the keyboard can be used to walk around 
the temple, while in the VR the user can teleport to one position to the other by using the space bar.

An introduction video, showing the point cloud reconstruction of the outside of the temple, was added at the beginning of both the game and the VR.

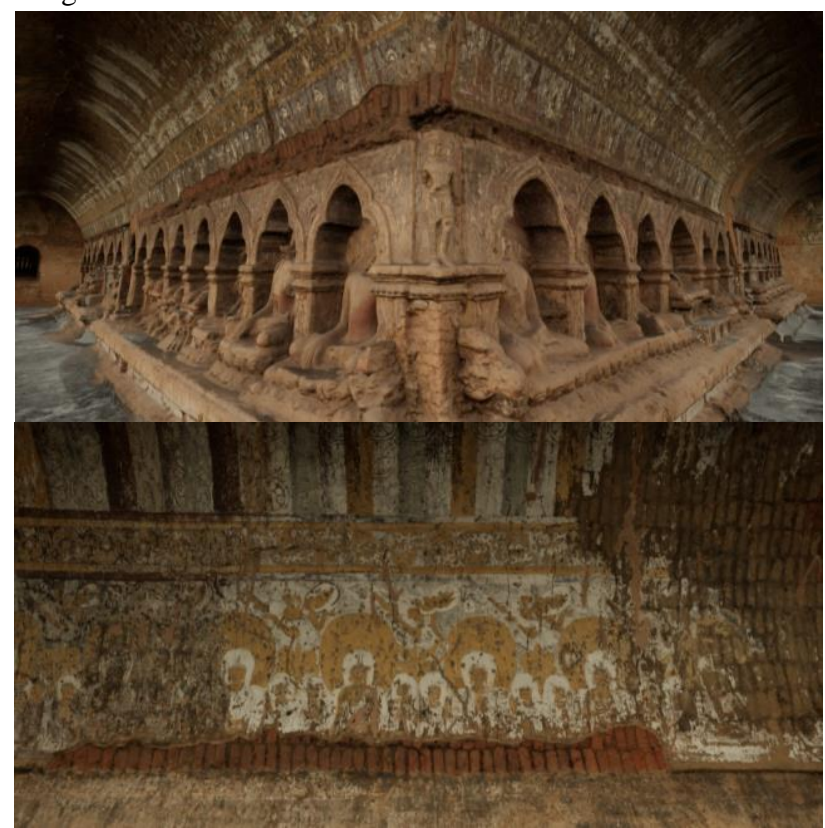

Figure 6. Screenshots from the Virtual experience: walls and ceiling

\subsection{Evaluation user study}

In order to evaluate how both the VR and the serious game enhance the communication of architectural heritage to the public, and potentially raising their awareness on the cultural value of Myin-pya-gu, a preliminary User Study has been conducted. Participants were recruited to take part in the study individually in order to dedicate them all the required assistance and attention. They were at first asked to sign an informed consent form and they were then given basic information about the study itself, its aims and organization. They were also informed of the low risk of feeling disoriented using VR headset and of the possibility of stopping the test at any time. Some general questions regarding their age, gender, profession, familiarity with video games and Virtual Reality experiences were asked before starting.

The study lasted 25 minutes on average and participants were asked to analyse some standard information materials (pictures, drawings and maps) before they could try the serious game and the VR experience (Figure 7). The study deployed a mixedmethod evaluation, consisting:

- Questionnaire with both multiple choice and open questions to evaluate the grade of understanding

- Observation of participants' reactions to the different proposed materials (how much time they spent examining the standard materials and then using the game and the VR);

- Sketching a simplified cross-section of the corridor to evaluate the participants' perception of the interior dimensions of the temple by providing them with a grid paper (including a silhouette of an average tall person to maintain the scale).

- User Experience Questionnaire (ueq-online.org) to assess participants' overall VR experience.
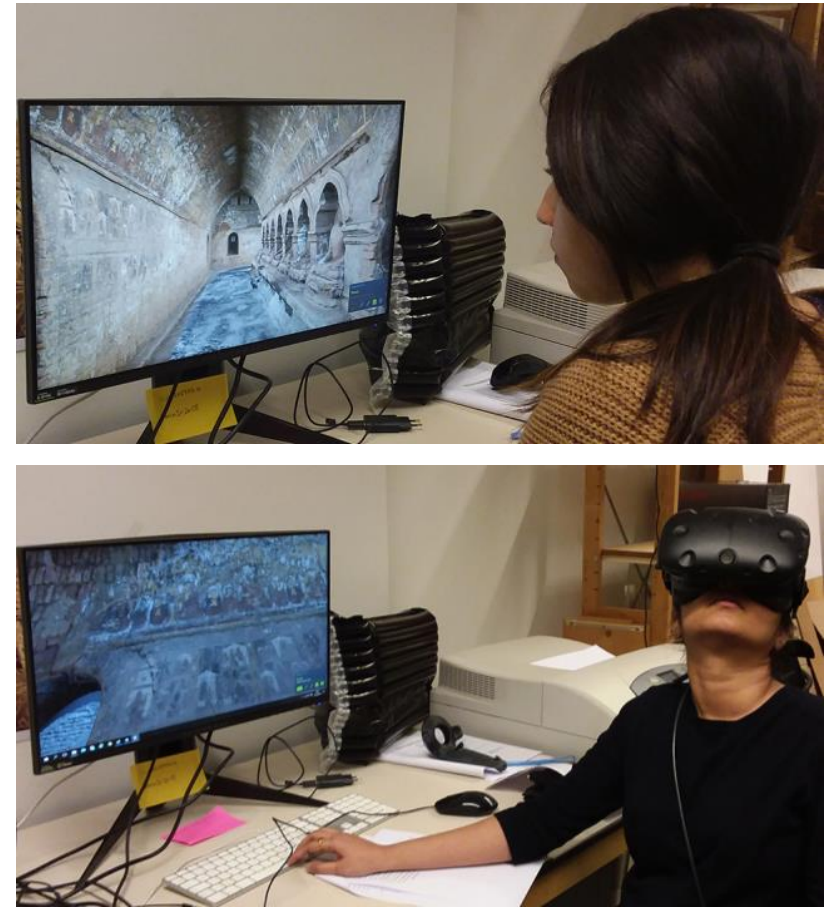

Figure 7. Participant trying the game and the VR experience

\section{RESULTS}

The user study involved a total number of 13 participants; seven females and six males, between 24 and 30 years, participated in the test. The vast majority $(\mathrm{N}=11)$ was working or studying in the conservation field and seven $(\mathrm{N}=7)$ people had already tried a VR experience in a previous occasion.

\subsection{Standard information materials: pictures and drawings}

First of all, some pictures and drawings representing the setting, the exteriors and the interiors of Myin-pya-gu temple were shown to the participants. The intent of this procedure was to evaluate how much attention people pay on standard materials normally used to give information about inaccessible sites. During this phase, participants were timed and no limit was imposed. The average time spent on analysing the standard information materials was of 1 minute and 28 seconds, with a minimum of 40 seconds and a maximum of 3 minutes and 12 seconds.

Then, the participants answered some questions about the state of conservation of the building, its materials and decorative elements. When asked about which materials they could recognize from the pictures, five $(\mathrm{N}=5)$ participants identified bricks, only one $(\mathrm{N}=1)$ wood and three $(\mathrm{N}=3)$ recognized plaster with paintings. Furthermore, nine $(\mathrm{N}=9)$ people thought that stone was one of the used materials, but sculptures were actually made of plastered and painted bricks.

Talking about the sculptures representing the Buddhas, five $(\mathrm{N}=5)$ participants wrongly assessed that they were in low relief and eight $(\mathrm{N}=8)$ people could not recognize any difference between the statues. On the other hand, five $(\mathrm{N}=5)$ participants noticed that some sculptures were more damaged than others. Moreover, nine $(\mathrm{N}=9)$ of the participants could not describe any of the elements represented on the mural paintings, while three $(\mathrm{N}=3)$ of them recognized geometrical and floral motifs and only one $(\mathrm{N}=1)$ noticed the presence of human figures. 


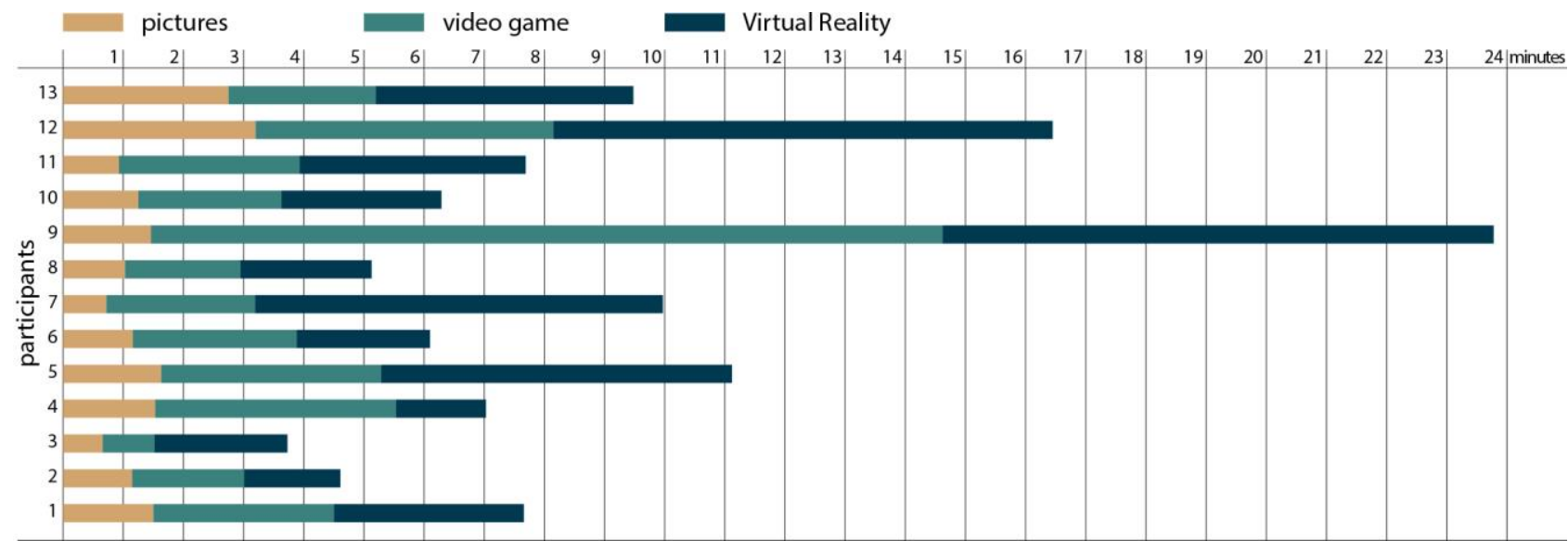

Figure 8. Chronological analysis of participants' interaction

\subsection{Serious game and Virtual Reality experience}

Participants were then invited to try the serious game and the Virtual Reality experience. As for the analysis of the standard information materials, they were timed and no restrictions were provided. The average time spent using the video game was of 3:34 minutes, with a minimum of 52 seconds and a maximum of 13:10 minutes, while for the VR the registered average time was of 4:08 minutes, with a minimum of $1: 30$ and a maximum of 9:10 minutes (Figure 8). For the Virtual Reality, an HTC Vive Head Mounted Display (HMD) was used for an immersive firstperson experience. Participants were thus asked to fill in a questionnaire that was identical to the one they received after looking at the standard information materials. It is important to underline that they were not aware of the fact that they would have had to answer again to those questions. By comparing the results, it was possible to notice a general improvement in the recognition of the materials. Four $(\mathrm{N}=4)$ more participants recognized bricks $(+80 \%)$, three $(\mathrm{N}=3)$ plaster $(+100 \%)$ and two $(\mathrm{N}=2)$ wood $(+200)$, but more importantly two $(\mathrm{N}=2)$ participants understood that sculptures were not actually made of stone (-22\%) (Figure 9).

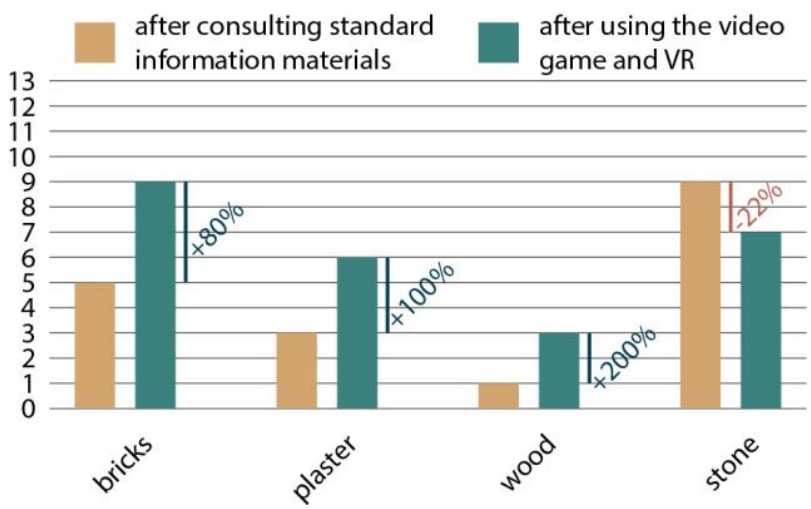

Figure 9. Recognized materials

After using the video game and the VR, all the participants noticed that the sculptures were in high relief $(+62 \%)$ and several differences between the various Buddhas were identified. Nine $(\mathrm{N}=9)$ participants noticed the different state of conservation of the sculptures, especially referring to the absence of some of the heads $(+80 \%)$, while for the first time eight $(\mathrm{N}=8)$ participants realized that not all the Buddhas were seated and other three $(\mathrm{N}=3)$ recognized differences in colour (Figure 10).

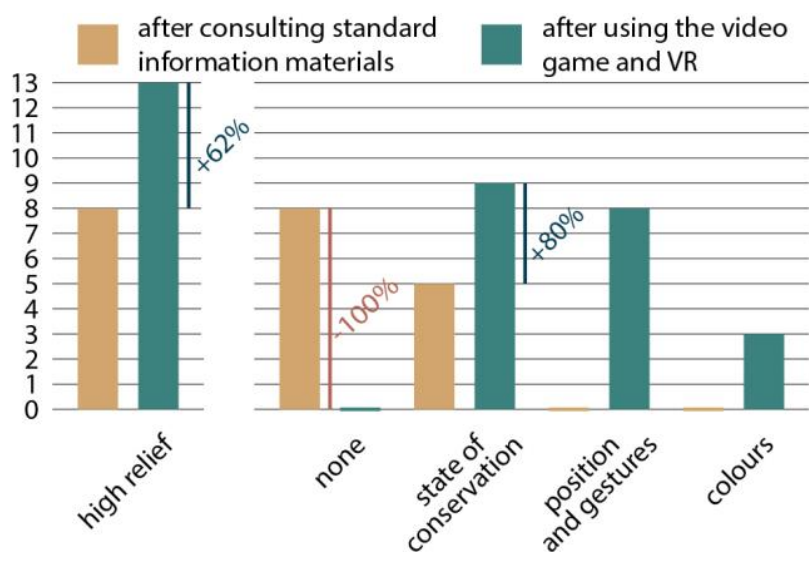

Figure 10. Recognized features of the sculptures

For what concerns mural paintings, all the participants were this time able to identify some of the represented items. The majority $(\mathrm{N}=11)$ noticed the presence of human characters and other ten $(\mathrm{N}=10)$ participants referred to have seen geometrical and floral patterns. Moreover, five $(\mathrm{N}=5)$ participants recognized blue, red and white temples (Figure 11).

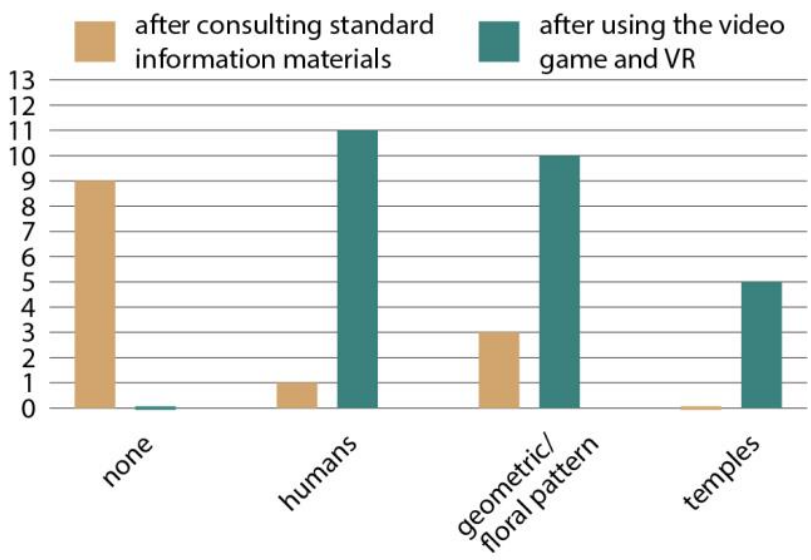

Figure 11. Recognized motifs of the paintings

Both after consulting the standard information materials and trying the game and the VR experience, the participants were also asked to evaluate the state of conservation of Myin-pya-gu. After the use of the videogame and of the VR, the value dropped dramatically, meaning that these tools improved the communication not just of the artistic and architectural features of the temple but also of its fragile condition. 


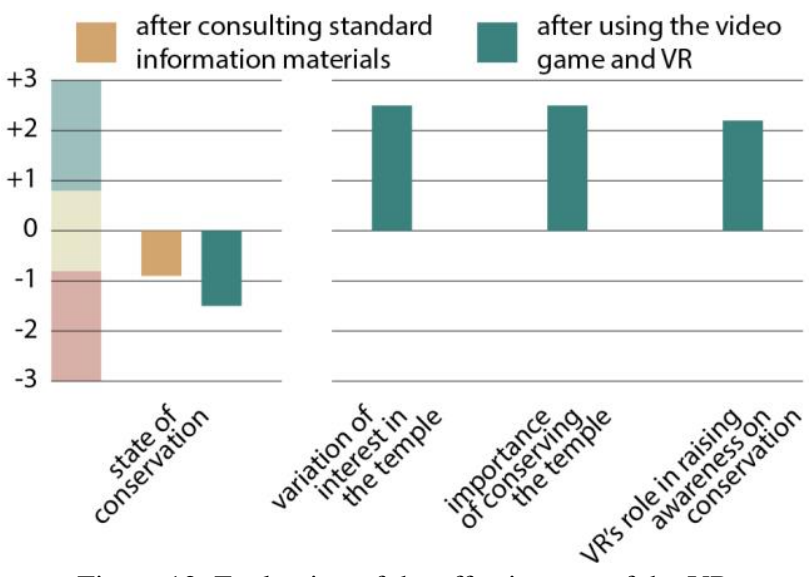

Figure 12. Evaluation of the effectiveness of the VR

The participants were then asked to answer few further questions only after they had tried the video game and the VR experience. The results showed that these tools highly contributed to raise interest in the temple and awareness on the importance of conserving and restoring it (Figure 12).

When asked to suggest possible implementation to the game and the VR experience, three $(\mathrm{N}=3)$ participants answered they would have not modified anything, while other three $(\mathrm{N}=3)$ suggested that it would have been interesting to explore also the outside of the temple. Other suggestions included the possibility of controlling the lightening $(\mathrm{N}=2)$ and go closer to the ceiling to better analyse the mural paintings $(\mathrm{N}=2)$, but the most popular request regarded the addition of audio $(\mathrm{N}=3)$ and written $(\mathrm{N}=5)$ information when pointing at some specific items.

This last suggestion would be certainly important when using the game and the VR for communication and tourism purposes, while the control of luminosity and the possibility to zoom on some elements of interest would be precious tools for monitoring and conservation goals.

In general, the graphic quality of both the game and the VR was evaluated as very high and the participants almost unanimously agreed that this aspect highly contributed to the enjoyment of the virtual experience (Figure 13).

If on one side every participant preferred VR overall, there was disagreement about the best way of exploring the virtual model. Five $(\mathrm{N}=5)$ participants preferred the "walking" method used in the video game because considered more natural, while the other nine ( $\mathrm{N}=9)$ assessed that the "teleportation" method used for the VR was better because it allowed the user to concentrate on what he was looking at instead of on the movement.
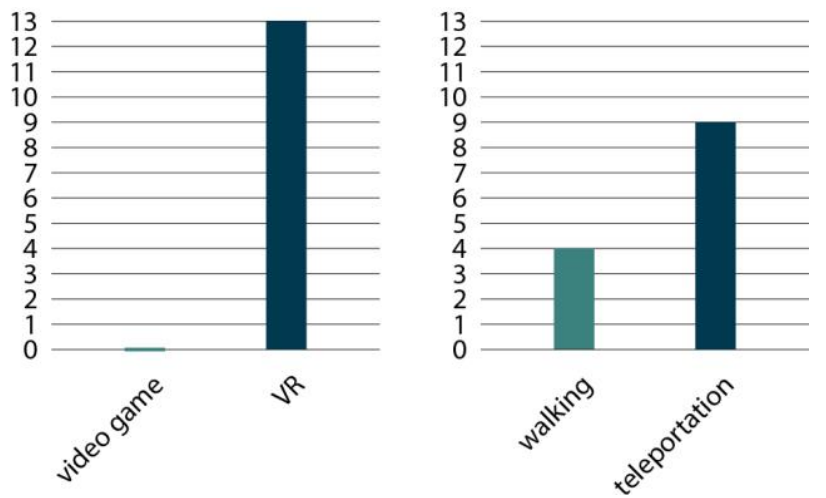

Figure 13. Evaluation of the preferred tool and way of moving

\subsection{Communicating the spatial dimensions and proportions of the temple}

The ability of the serious game and the VR experience to communicate the spatial dimensions of the temple was also took in consideration for the user study. The participants were asked to estimate the height, width and length of the corridor inside Myin-pya-gu temple via sketching a cross-section, but since these dimensions do actually variate quite a lot according to the place they are measured in, all the answers included between the maximum and minimum registered values of the three dimensions were considered correct.

The right width of the corridor was guessed by five $(\mathrm{N}=5)$ of the participants $(38 \%)$, while other seven $(\mathrm{N}=7)$ were wrong by less than $15 \%$ and only one $(\mathrm{N}=1)$ guessed a width that was more than 30\% larger than the real one. On the other hand, only two $(\mathrm{N}=2)$ participants estimated the right height of the corridor, while eight $(\mathrm{N}=8)$ participants proposed values less than $15 \%$ higher or lower than the correct one, two $(\mathrm{N}=2)$ were wrong by less than $30 \%$ and one $(\mathrm{N}=1)$ indicated a value that was lower than the correct one by $37 \%$. However, it is quite interesting to notice that, considering the width/height ratio, the $77 \%(\mathrm{~N}=10)$ of the participants were right. This result underlines the tendency to perceive the correct proportions more than the exact dimensions. The sketches of the cross-section of the corridor show that all the participants recognized that the space was vaulted and four $(\mathrm{N}=4)$ of them even drew the profile of the niche hosting the sculptures of the Buddhas (Figure 14).

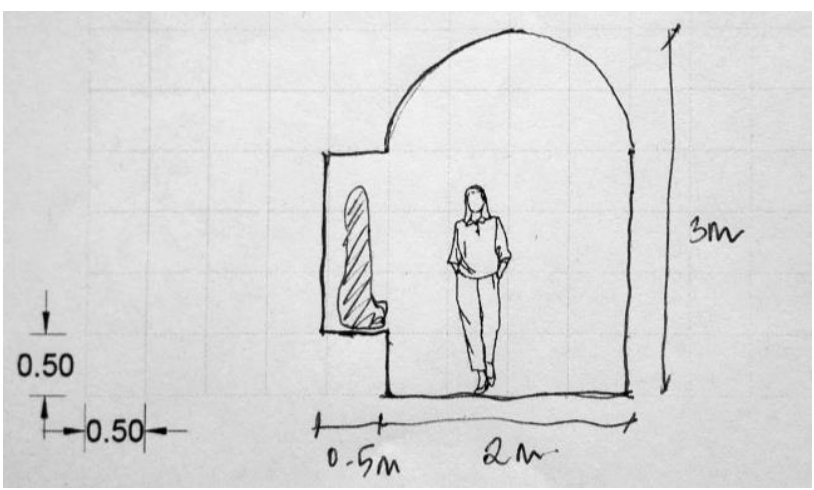

Figure 14. The section drawn by one of the participants

For what concerns the length of the corridor, seven $(\mathrm{N}=7)$ people estimated the right value and two $(\mathrm{N}=2)$ of them were wrong by $5 \%$, while four $(\mathrm{N}=4)$ people estimated a length that was between 30 and $50 \%$ shorter than the actual one (Figure 15). The fact that nobody estimated a longer length and that $46 \%$ of the participants perceived the hallways as shorter than they actually are, conforms the results of previous studies that users of Head Mounted Displays tend to underestimate distances by $26 \%$ (Pietroni et al., 2018). This aspect should be further investigated in order to provide solutions that will enhance the communication of dimensions through the VR mediums.

In general, the game and the Virtual Reality allowed the participants to understand the volumetric dimension of Myinpya-gu's inner space. The lack of correct answers for what concerns the height of the corridor might be addressed to the fact that the participants were not allowed to adjust the point of view according to their own height. Both the game and the VR experience were indeed calibrated on an average height of 1.70 meters. Future studies should therefore either provide the possibility to change the height of the point of view or the participants should be asked to write their own height. 

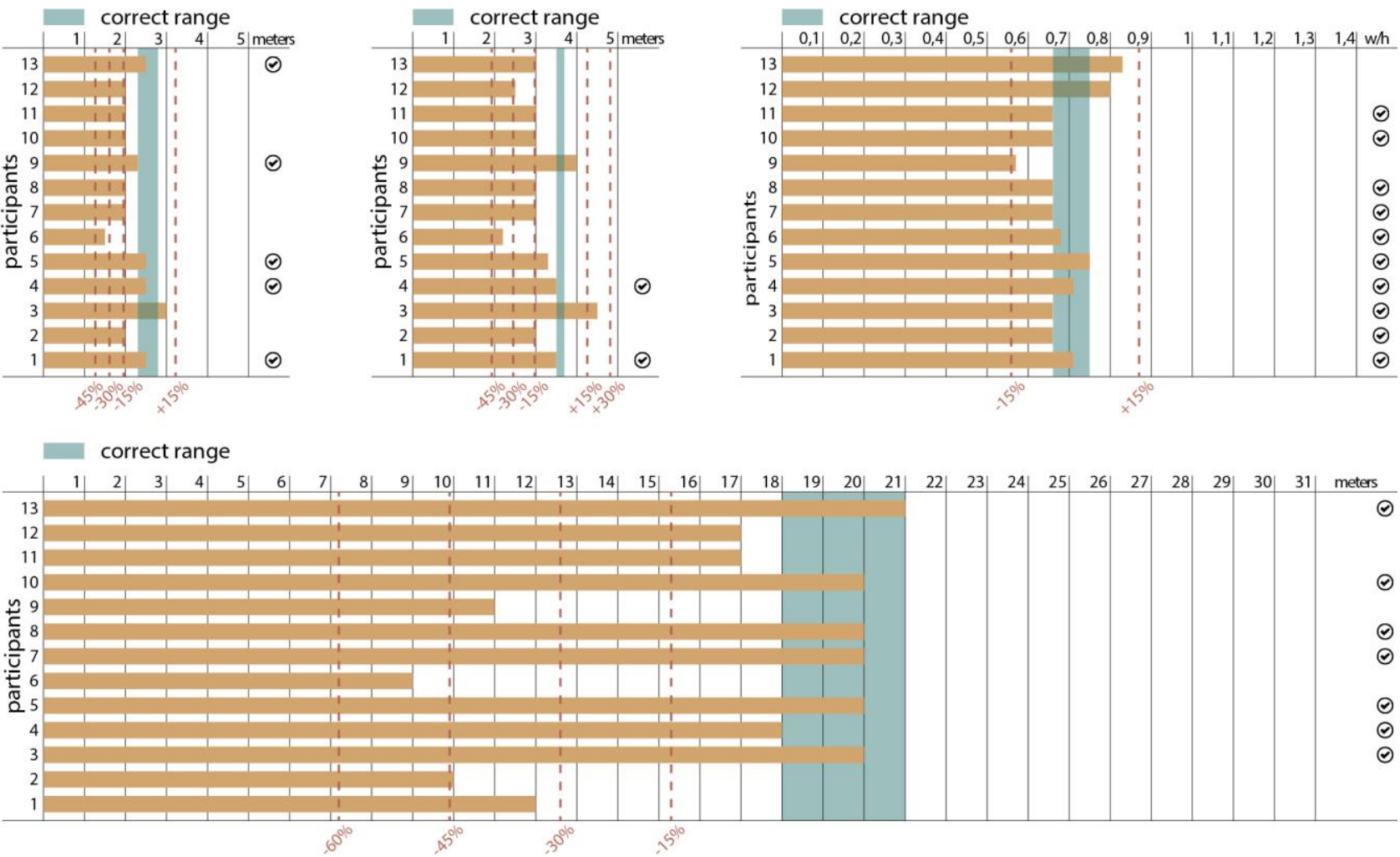

Figure 15. Dimensions estimated by the participants. Width, Height and W/H (top), Length (bottom)

\subsection{User Experience Questionnaire}

Finally participants were asked to fill in a standardized user experience questionnaire (UEQ) adapted for the occasion. The original UEQ is indeed made of six different scales (Attractiveness, Efficiency, Perspicuity, Dependability, Stimulation and Novelty) for a total of 26 items, but only the 14 questions regarding the scales of Attractiveness (the general impression of users), Perspicuity (whether the game and VR were easy to understand) and Stimulation (valuating the interest and excitement of participants) were taken into account for this User Study. The reasons that lead to this choice are related with the will of making the questionnaire easier for the participants by avoiding parameters that could be unclear and that were not considered interesting for the purposes of this study.

Participants were asked to express their opinion on both the serious game and the VR experience on a scale that goes from 3 (representing the most negative answer) to +3 (representing the most positive answer) and the results are shown in Figure 16.

The values between $-0,8$ and $+0,8$ represent more or less neutral evaluation of the corresponding scale, values $>0,8$ stand for a positive appreciation and values $<-0,8$ refer to a negative rating (Nofal et al, 2018). On the other hand, the error bars show the confidence interval, which is the area where the true value of the scale mean should be located with a 95\% probability. Therefore, big error bars stand for a not very precise measurement and this can be caused by an inadequate sample size.

From the data collected during this user study, it is evident that both the game and the VR got very high results for all the three scales applied. The VR generally got higher values and smaller error bars, indicating that the results are quite reliable.

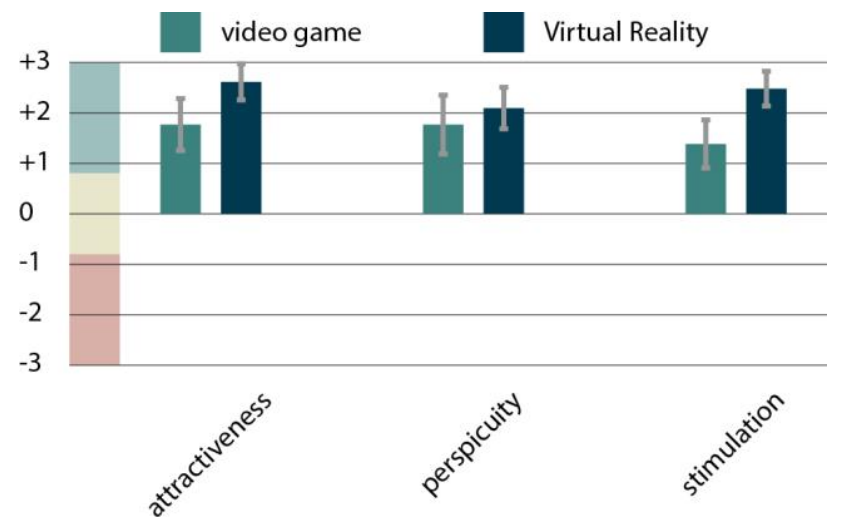

Figure 16. Results of the UEQ (the error bars represent the 95\% confidence intervals of the scale mean)

\section{CONCLUSIONS}

This paper has presented Myin-pya-gu temple in Bagan as a case study for the application of Virtual Reality technology to provide accessibility whenever safety and fragility reasons prevent both visitors and experts from physically accessing a site.

The VR has been highly appreciated for its attractiveness, perspicuity and stimulation, but, more importantly, it has proved to be very effective in allowing users to recognize materials, features and state of conservation of the temple. The high resolution and the level of detail, that characterize the virtual tools developed for Myin-pya-gu, have contributed not just to the enjoyment of the users but also to the actual understanding of the temple's features and dimensions. Furthermore, after having tried the game and the VR experience, the large majority of the participants has 
experienced a relevant increase both in their interest in the temple and in the recognition of the importance of conserving it.

These results demonstrate that these technologies can raise awareness about cultural heritage among users and actively help conservation experts in their research.

Future work involves the implementation of lightening and contrast control for the optimization of the VR experience and a better-detailed observation of the features of the building.

The inclusion of sounds and the development of interactive ways to access information are also objects of future research that looks at enhancing the qualities of VR as a working tool.

\section{ACKNOWLEDGEMENTS}

The authors wish to thank Myanmar's Department of Archaeology, National Museum and Library (DoA) for the opportunity to collaborate in the documentation of this temple. Special thanks also goes to Carleton Immersive Media Studio (CIMS) and the students from Carleton University and Mandalay Technological University who assisted in the 3D capture during the workshop. This work was supported by the NSERC Create Heritage Engineering program at Carleton University.

\section{REFERENCES}

Arenghi, Alberto and Andrea Pane. "The Addition in Conservation Project for the Accessibility to Cultural Heritage." Techne: Journal of Technology for Architecture and Environment no. 12 (2016): 57-64.

Conti, Christina and Ilaria Garofolo. "AA_AccessibleArchaeology. Environmental Accessibility as a Key to Enhance Cultural Heritage." Techne: Journal of Technology for Architecture and Environment no. 7 (2014): 140-148.

Dhanda, A., Reina Ortiz, M., Weigert, A., Paladini, A., Min, A., Gyi, M., Su, S., Fai, S., and Santana Quintero, M.: RECREATING CULTURAL HERITAGE ENVIRONMENTS FOR VR USING PHOTOGRAMMETRY, Int. Arch. Photogramm. Remote Sens. Spatial Inf. Sci., XLII-2/W9, 305310, https://doi.org/10.5194/isprs-archives-XLII-2-W9-3052019, 2019

John, D., L. Shaw, P. Cheetham, H. Manley, A. A. Stone, M. Blakeburn and K. Gosling (2017). "Educational Virtual Reality Visualisations of Heritage Sites", EUROGRAPHICS Workshop on Graphics and Cultural Heritage.

Koller, A., "Architectural Design at Bagan and Angkor: A Comparison." Journal of the Royal Asiatic Society 27, no. 1 (2016; 2017): 1-49.

Luce, Gordon Hannington, Bha Rhan and Tin Co U. 1969. Old Burma-Early Pagán. Locust Valley. New York: Artibus Asiae and the Institute of Fine Arts, New York University.

McDermott, W., 2018. The PBR Guide Volume 2: Practical Guidelines for Creating PBR Textures, Allegorithmic https://www.allegorithmic.com/pbr-guide (27 October 2018). Oculus, 2018. Oculus Quest, https://www.oculus.com/quest/ (27October 2018).
Nofal, E., Stevens, R., Coomans, Th., and Vande Moere, A. "Communicating the Spatiotemporal Transformation of Architectural Heritage via an In-situ Projection Mapping Installation." Digital Applications in Archaeology and Cultural Heritage 11 (2018): $\quad$ E00083, https://doi.org/10.1016/j.daach.2018.e00083.

Nordic Council of Ministers. Accessibility to Cultural Heritage: Nordic Perspectives. Copenhagen K: Nordic Council of Ministers, 2009.

Pichard, P. 1992-2002. Inventory of Monuments at Pagan, KISCADALE EFEO UNESCO.

Pietroni, E., Pagano, A., \& Fanini, B. (2018). UX Designer and Software Developer at the Mirror: Assessing Sensory Immersion and Emotional Involvement in Virtual Museums. Studies in Digital Heritage, 2(1), 13-41. https://doi.org/10.14434/sdh.v2i1.24634

Puyuelo, Higón, Merino, and Contero. "Experiencing Augmented Reality as an Accessibility Resource in the UNESCO Heritage Site Called "La Lonja", Valencia." Procedia Computer Science 25, no. C (2013): 171-78.

Remondino, F., Nocerino, E., Toschi, I., Menna, F., 2017. A Critical Review of Automated Photogrammetric Processing of Large Datasets. In: Int. Arch. Photogramm. Remote Sens. Spatial Inf. Sci., Vol. XLII-2/W5, pp. 591-599, doi.org/10.5194/isprs-archives-XLII-2-W5-591-2017.

Scarpati, D. (2016), "Accessibility for a democratic Museum", in Greco, A., Giacometti, V. (Eds.), Improving the Accessibility of the Cathedral in Milano: approaches and results of the workshop I AM Duomo, Quaderni dell'Almo Collegio Borromeo, Pavia, pp. 119-127.

Stadtner, D. M. (2013). Ancient Pagan. Buddhist Plain of Merit. Bangkok: River Books.

Treccani, G.P., Arenghi, A. (2016), "Different Design Approaches to Accessibility to Cultural Heritage: a Decalogue", in Arenghi, A., Garofolo, I., Sørmoen, O. (Eds), Accessibility as a Key Enabling Knowledge for Enhancement of Cultural Heritage, Franco Angeli, Milano, 2016, pp. 105-114.

Zhou, Mingquan, Guohua Geng, Zhongke $\mathrm{Wu}$, and SpringerLink (Online service). Digital Preservation Technology for Cultural Heritage. 1. Aufl.;2012; ed. Vol. 9783642280993. Beijing;New York;Berlin;: Springer, 2012. doi:10.1007/978-3642-28099-3 